\title{
AR Learning Environment Integrated with EIA Inquiry Model: Enhancing Scientific Literacy and Reducing Cognitive Load of Students
}

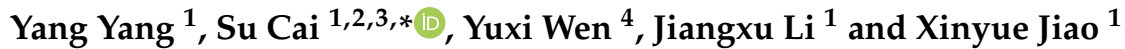 \\ 1 VR/AR+ Education Laboratory, School of Educational Technology, Faculty of Education, Beijing Normal \\ University, Beijing 100875, China; 201721010202@mail.bnu.edu.cn (Y.Y.); 202121010204@mail.bnu.edu.cn (J.L.); \\ 202021010198@mail.bnu.edu.cn (X.J.) \\ 2 Beijing Advanced Innovation Center for Future Education, Beijing Normal University, Beijing 100875, China \\ 3 Research Institution of Science Education, Beijing Normal University, Beijing 100875, China \\ 4 Department of Teaching and Learning, Peabody College of Education and Human Development, \\ Vanderbilt University, Nashville, TN 37240, USA; yuxi.wen@vanderbilt.edu \\ * Correspondence: caisu@bnu.edu.cn
}

Citation: Yang, Y.; Cai, S.; Wen, Y.; Li, J.; Jiao, X. AR Learning Environment Integrated with EIA Inquiry Model: Enhancing Scientific Literacy and Reducing Cognitive Load of Students. Sustainability 2021, 13, 12787. https:// doi.org/10.3390/su132212787

Academic Editors: Gwo-Jen Hwang, Haoran Xie and Xiao-Fan Lin

Received: 10 October 2021

Accepted: 15 November 2021

Published: 19 November 2021

Publisher's Note: MDPI stays neutral with regard to jurisdictional claims in published maps and institutional affiliations.

Copyright: (c) 2021 by the authors. Licensee MDPI, Basel, Switzerland. This article is an open access article distributed under the terms and conditions of the Creative Commons Attribution (CC BY) license (https:/ / creativecommons.org/licenses/by/ $4.0 /)$.

\begin{abstract}
This study constructed the EIA (Experience-Inquiry-Application) model to evaluate its extent on promoting scientific inquiry activities under an AR learning environment in an upper primary science course setting. Two hundred and nine fifth-grade Chinese students were randomly assigned to one of the three conditions, as a quasi-experiment was conducted to investigate how the EIA model and the AR learning environment influence students' science learning. Both quantitative and qualitative data were collected. Quantitative data suggest that students who participated in the EIA model under the AR setting performed the best; it also gives evidence to support that both the EIA model and the AR environment has significant positive effects on students' performance in science learning. Qualitative data, in the form of a semi-structured interview with teachers and students, reveal that AR is able to be used for experiments that were originally deemed impossible, and it inspires students' motivation for knowledge acquisition. Moreover, the EIA model empowers students in small-group collaboration, and is a good pedagogical tool to summarize units. EIA and AR form a bond of theory and technology and it strengthens students in manifold ways when it is deeply interwoven.
\end{abstract}

Keywords: AR learning environment; EIA model; scientific literacy; cognitive load

\section{Introduction}

Augmented reality (AR), the technology of integrating virtual objects with the real world, has the following three defining characteristics: (a) Combines real and virtual objects in a real environment; (b) Runs interactively and synchronously; (c) Registers real and virtual objects with each other [1,2]. Based on these characteristics, AR has been proven to have great potential educational affordances which are especially useful in the sciences, including spatial ability, practical skills, scientific inquiry learning, and conceptual understanding [3]. Although the role of AR in science education has been relatively clearer than other core subjects, the methods in which AR environments and learning activities coalesce remain an open question [4,5]. Since there are distinctive features within AR instructional approaches compared to conventional teaching methods [4], researchers should attempt to develop holistic models for AR teaching to adapt to the pedagogical changes of AR [5].

In China, AR is regarded as an important medium to enrich students' scientific inquiry experience by experts and policy-makers in public education. Administrative guidelines from the Chinese Ministry of Education, especially Instructions on Strengthening and Reforming Experimental Teaching in Primary and Secondary Schools, states that 
"Augmented Reality (AR) and Virtual Reality (VR) can be used to observe a phenomenon that is difficult to observe and control in practical settings; a phenomenon that changes at a rate too fast or too slow in real time; experiments that are considered dangerous, destructive, or environmentally hazardous" [6]. With that being said, Chinese classroom teachers still consider AR as a new technology because it is seldom used in classes [7]. Some of the hesitation might come from the fact that classroom teachers experience difficulty finding adequate, structured, and high-quality AR teaching resources that correspond to their everyday lessons; a deeper reason that could be reasonably speculated is that since the $\mathrm{AR}$ teaching and learning environment requires a shift in learning perspectives, as students need to change from a mindset of rote remembering into actively acquiring and processing information, this demands significant amendments in pedagogy from the teacher's end [7]. Therefore, such drastic calls could factor into the current reality where teachers remain prudent on such technologies.

In light of these facts, and in order to support and further scientific inquiry activities in primary schools, this study attempts to propose an inquiry model suitable for AR environments and verify the adaptability of this model to primary science teaching in AR environments through a quasi-experiment.

\section{Literature Review}

\subsection{AR Experimental Environment of Primary School Science}

In recent years, AR has attracted attention from a wide range of researchers in the domain of teaching primary school science, and such literature covers many sub-fields, such as Physical Sciences [8,9], Life Sciences [10-12], and Earth and Space Sciences [13,14]. In these different sub-fields, AR tends to play different roles. For example, in the area of Physical Sciences, AR is used to support some unavailable experiments, such as microscopic particles and the magnetic field [15-18]. In the Life Sciences, multiple articles investigate the effects of using AR to guide students to explore a real outdoor space with AR-generated clues $[10,12,19]$. When it comes to Earth and Space Sciences, AR assists students to record and analyze their long-term observations of phenomena $[13,14]$. In addition, these studies consider many supportive strategies suitable for AR teaching, including text reminders [20], collaborative scaffolds [15], repertory grids [21], and concept maps [11].

According to the literatures, it is clear that AR can be a helpful tool in empowering students' comprehensive scientific literacies, such as observation, inquiry, and analysis, when they are engaged in science learning. Compared to other traditional classroom technologies such as Flash or video clips, AR can be used in conjunction with other support tools, meaning that AR is powerful when comes to constructing learning spaces.

Thus, it is obvious that the field has studied out-of-classroom learning spaces and specific abilities to a good extent. As AR becomes more well-known and pertinent to everyday teaching and learning, it is natural to move from more fundamental, abilityspecific inquiries to a more integrated, rounded perspective to examine such technology. One good candidate for the requirements is to consider students' scientific literacies, so that this can potentially collaborate with AR to transform the classroom into a more suitable learning space for the students themselves. Therefore, it is now appropriate to introduce the idea of primary students' scientific literacy.

\subsection{Scientific Literacy}

Scientific literacy is the ability to engage with science-related issues; in other words, this suggests that a scientifically literate person is able to understand science, the nature of scientific knowledge and the relationship of science with society and environment, to know basic scientific concepts, laws, theories and principles, and to use science process skills [22]. Scientific literacy has been globally recognized as a major goal of science education [23], and many educators that specialize in evaluation and assessment pay close attention to such an issue and tend to approach it from multiple dimensions. For example, the PISA (Program for International Student Assessment) evaluates test-takers' scientific literacy from three 
aspects: (a) to explain a phenomenon scientifically; (b) to evaluate and design scientific enquiry; and (c) to interpret data and evidence scientifically [24]. It is then reasonable to infer that according to educators and developers for PISA, these aspects are considered pillars to understand and engage in critical discussions on issues that involve science and technology. Science curriculum scholars from China have put forward eight inquiry activities related to scientific literacy: posing questions, raising hypothesis, making plans, collecting evidence, processing information, drawing conclusions, communicating and presenting, and evaluating and reflecting [25]. These foundational and policy-wise pieces of literature are valuable references when considering and designing AR-based scientific inquiry, as the activities above could be taken on in the process.

\subsection{Cognitive Load}

Cognitive load is another important factor that needs further discussion in the scientific activities on the basis of AR [5]. Since our working memory is limited, there is a finite range for the amount of information we can deal with simultaneously and the time that the information can be retained, and information exceeding the limit could lead to cognitive load [26]. Cognitive load also occurs when we adopt a new technology for learning with an inappropriate order of relevant activities [27]. Thus, learning content and activities sequences should be taken into consideration according to AR's characteristics to reduce students' cognitive load. The cognitive load can be measured from two dimensions, namely "mental load" and "mental effort", respectively relating to intrinsic cognitive load and extraneous cognitive load [28]. A man with low mental load and high mental effort has a positive performance on cognitive load [21]. If the AR tool promotes distraction by presenting a lot of information, it will increase cognitive load for students [3]. Students will feel it is difficult to understand the learning content, and they may need to put great effort into completing the learning tasks or achieving the learning objectives in this learning activity [28]. Therefore, assistance in selecting and interpreting information in AR-based learning environments is required [3]. If the scaffolding mechanism can support better metacognitive processes, it might help with the aforementioned drawbacks of AR technology.

\subsection{Scientific Inquiry Model}

It is indisputable that primary science courses are essential in developing students' scientific literacy. In order to promote effective instructions in teaching primary science, researchers have proposed a variety of teaching and learning models, each with their own focuses. The learning psychologist and constructivist-driven 5E instructional model proposed by the BSCS (Biological Science Curriculum Study) has been widely applied and reiterated in the past 30 years or so $[29,30]$. 5E model's five discrete elements (engage, explore, explain, elaborate, and evaluate) have been used for references by many successors to build their own models. Eisenkraft [31] later added two activities, elicit and extend, to form the 7E model and emphasize the transfer of learning. Schwarz and Gwekwerere [32] constructed the EIMA model, standing for engaging topic, helping investigation, creating models and applying models to explain novel situations. Marshall, et al. [33] then built on top of EIMA and came up with the $4 \mathrm{E} \times 2$ model, highlighting the formative assessment and metacognitive reflection and reserving four inquiry activities: engage, explore, explain, and extend. Gunckel [34] designed the Inquiry-Application Instructional Model to support teachers focusing primarily on scientific inquiry, but also including aspects of conceptual change and cognitive apprenticeship.

In the case for China, scholars theorized during the national curriculum reform of Primary and Secondary Schools in 2001 that students' methods of approaching learning should be rooted in Independence, Investigation, and Collaboration, in which teachers pursue an inquiry teaching model such that it integrates educational technology and curriculum and instruction [35]. In that inquiry model, the teaching process is divided into five steps: (1) situational contextualization, (2) inspirational thinking, (3) independent in- 
vestigation, (4) cooperation and communication, and (5) summarization and improvement. Each phase of this model has specific corresponding resources, methods and activities [35].

In general, these models have their own advantages, yet it is difficult for them to seamlessly adapt into an AR-based environment for primary science's teaching and learning. Some major reasons include that current pedagogy is more focused on teacher-student interaction than participant-environment interactions. Moreover, the current pedagogy lacks mechanisms to promote active learning initiated by the students. Since student actions in AR-based learning environments are no longer in one-to-one correspondence with the teacher, student learning in such environments can take the paths of learning from the environment [8,10], learning from peers [9], and learning from their own construction [36]. Therefore, a good inquiry model that intends to suit AR learning environments must consider multiple factors, such as teacher role, classroom ecology, and situational context in addition to supporting the diversity and flexibility in students' individual learning.

\section{Context}

\subsection{EIA Inquiry Model}

In this study, the EIA model (Experience-Inquiry-Application) was constructed by the authors to support teachers in using AR environments for experiments that have real-life barriers to implementation, such that it enhances students' scientific literacies and reduces their cognitive load by combining existing theory and contemporary context. According to Turiman, Omar, Daud and Osman [22], a scientifically literate person is equipped with more than mere scientific knowledge and skills; they also have the ability to engage with science-related issues. Hence, mastering the inquiry process and application methods are just as important as internalizing scientific knowledge in science learning. Specifically, the EIA model functions under these operational definitions: experience is the accumulation of knowledge or skill that results from direct participation in events or activities; inquiry is the activity constructing explanations from patterns in experience with phenomena; application is the activity using scientific patterns and theories in new situations [35]. This definition corresponds to previous literature that teachers should help recall students' relevant prior knowledge about a phenomenon and prepare students to utilize this prior knowledge to be applied in a new context [31].

The EIA model contains three phases, which are Experience, Inquiry and Application. Each phase recognizes corresponding AR function, teacher activities and student activities, as shown in Figure 1. Compared to other models mentioned above, student activities in EIA model include learning activities and inquiry activities. Considering that evidence collection, processing information, and communication and presentation are the most common activities within phases, the EIA model exhibits the three activities as mediation between learning activities and other inquiry activities in each phase. This model also sees (a) posing questions and forming hypotheses; (b) creating models and drawing conclusions; and (c) conclusions and reflections as learning objectives in each phase. Among the student activities, the arrows represent various paths for students to achieve the inquiry goal and maintain the learning cycle, taking its ideas from the 5E model [31]. Students may arrive at inquiry activities directly from learning activities; they may also be inspired via numerous mediating activities. Despite the particular route students undertook, the experience of both mediating and inquiry activities encourages motivation in general learning activities. 


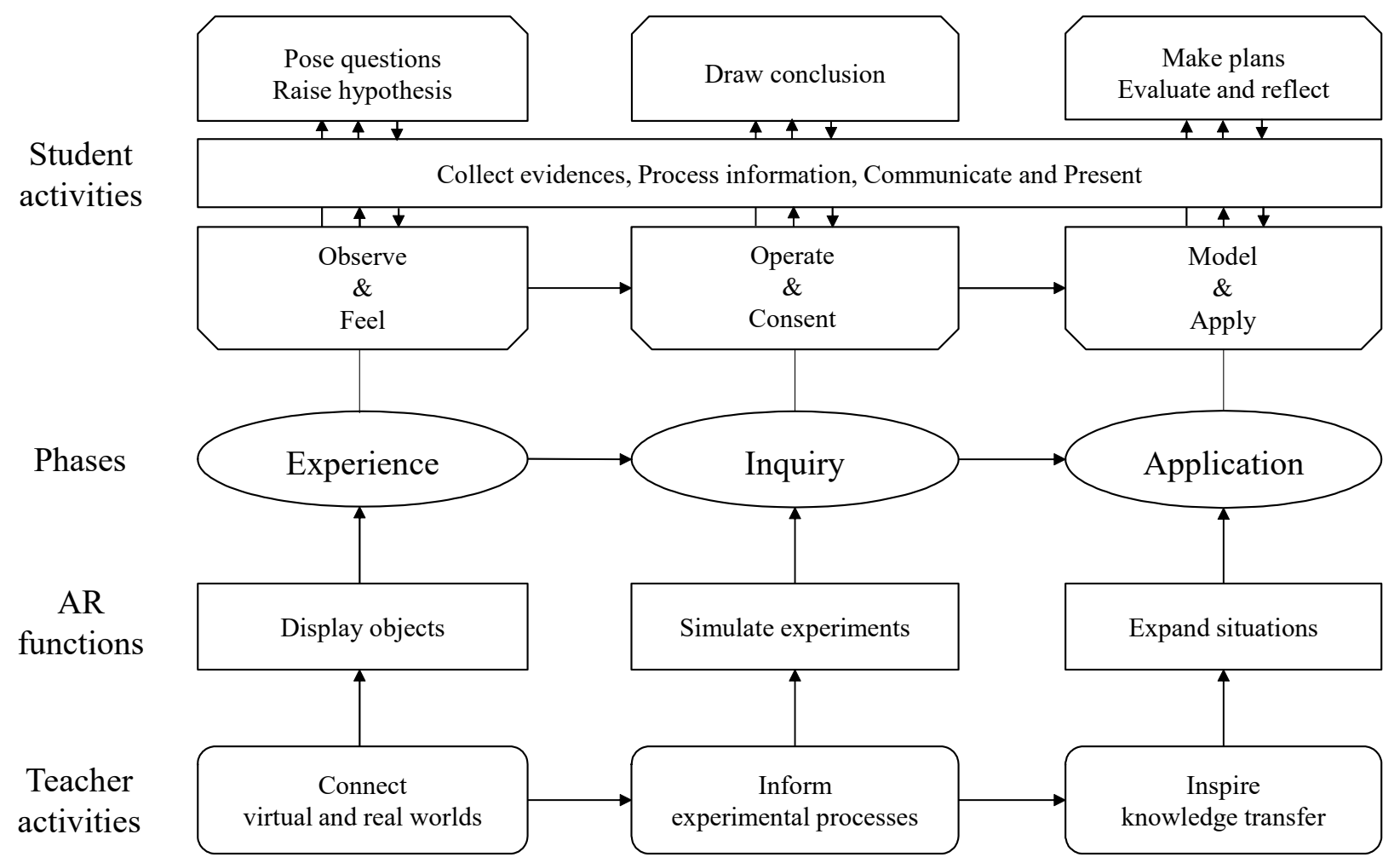

Figure 1. EIA inquiry model.

The EIA model treats experience as a separate phase in order to adapt to our limited working memory to avoid mounting cognitive load caused by a series of activities about prior experience and inspire teachers to evoke students' emotions and guide students to extract important objects and relationships through observation in the AR environments. In order to meet the common improvement of knowledge and skill, the EIA model counts inquiry and application as the other two phases. Teachers should inform students about the operation of AR experiments and assist students' teamwork about reaching conclusions in the inquiry stage. Given that transfer of learning is the key to the application stage, teachers are expected to inspire students to summarize their inquiry process or explanations of phenomena and apply the results in new situations took on by AR.

As shown in the EIA model, AR can provide appropriate support for student activities in all phases. Since AR is powerful in presenting the situation and context, AR is effective in helping students to recall prior knowledge, present designated phenomenon, and prepare students for the EIA process. If AR is presented at the beginning of class as a means to recall prior knowledge and introduce new material, it enables students' sense of presence, immersion and empathy, which is beneficial for discovering connections among objects and improving conceptual understanding [4,37]. In light of the characteristics of AR, students, with its help, can be cognitively and emotionally ready before the inquiry process, which is supportive for them to pose meaningful scientific questions. Then, to answer their own questions, students need to engage in a series of inquiries, including investigating, explaining and creating models $[30,32]$. During this time, the interactive AR environments can offer effective learning materials [38] and afford more efficient and explicit communication of information by the dynamic features of visualizations [9]. Thus, $\mathrm{AR}$ is conducive to teamwork and agreement in the inquiry [9]. For extrapolating to other cases, students are required to understand their own models and explain, justify, and defend their claims accordingly [32]. As AR visualizes the process in scientific matters [16], it can lead students to construct models one step at a time and highlight the similarities among different situations. In conclusion, AR environments are in favor of displaying scientific phenomena for inquiry and application. 


\subsection{AR Tools}

Referring to relevant content in the textbook and Curriculum Standards of Primary School Science Course [25], this study developed three AR learning environments: Secrets of the Stars, Secrets of the Seasons and Secrets of Shadows, based on the Unity3D Engine and the Vuforia AR toolkit. Each environment is divided into three parts to support learning activities about experience, inquiry and application. The contents and structure of these environments are shown in Figure 2.

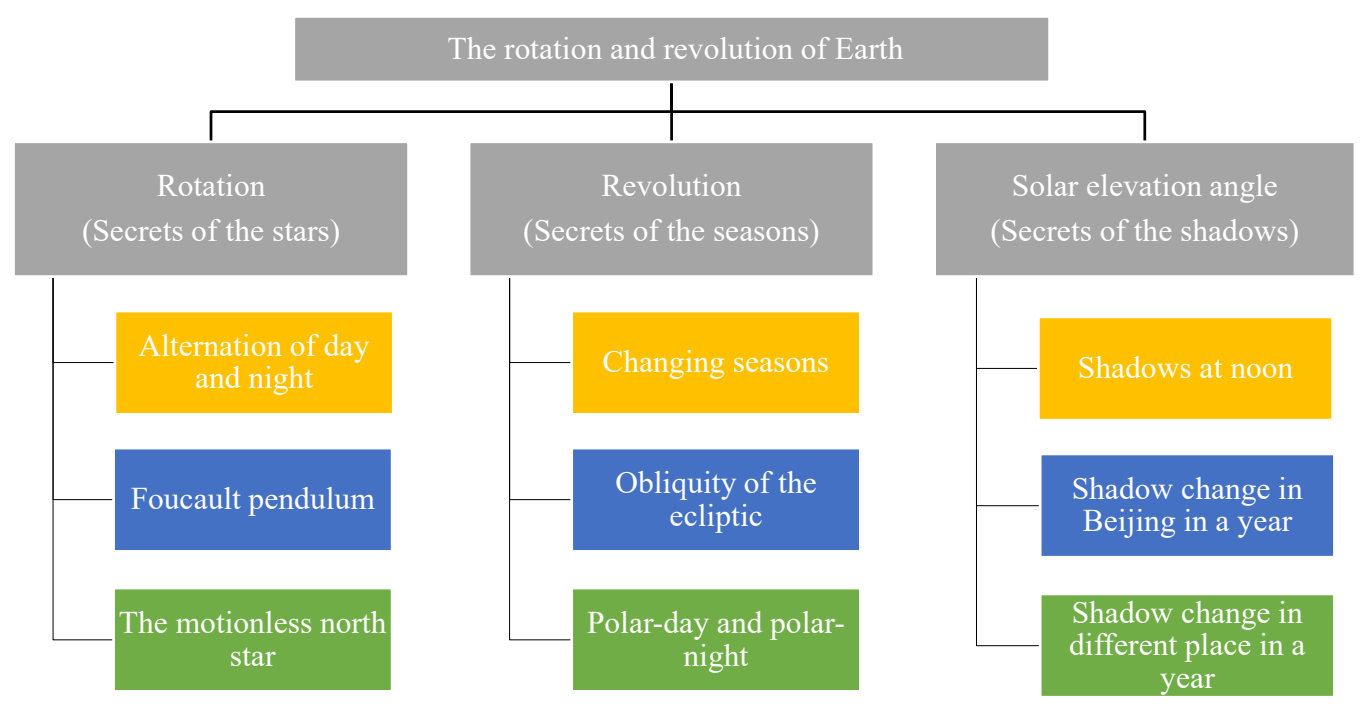

Figure 2. The contents and structure of the AR environments.

There are two mechanisms used in this study to combine virtual objects with the real world. In the inquiry and application parts of the first and third environment, image recognition was used to present simulation experiments on students' desks, as shown in Figure 3. In the experience part of all the environments and the entirety of the second environment, a gyroscope was used to set virtual objects according to directions, as shown in Figure 4. In these environments, users will see different scenes when facing different directions.

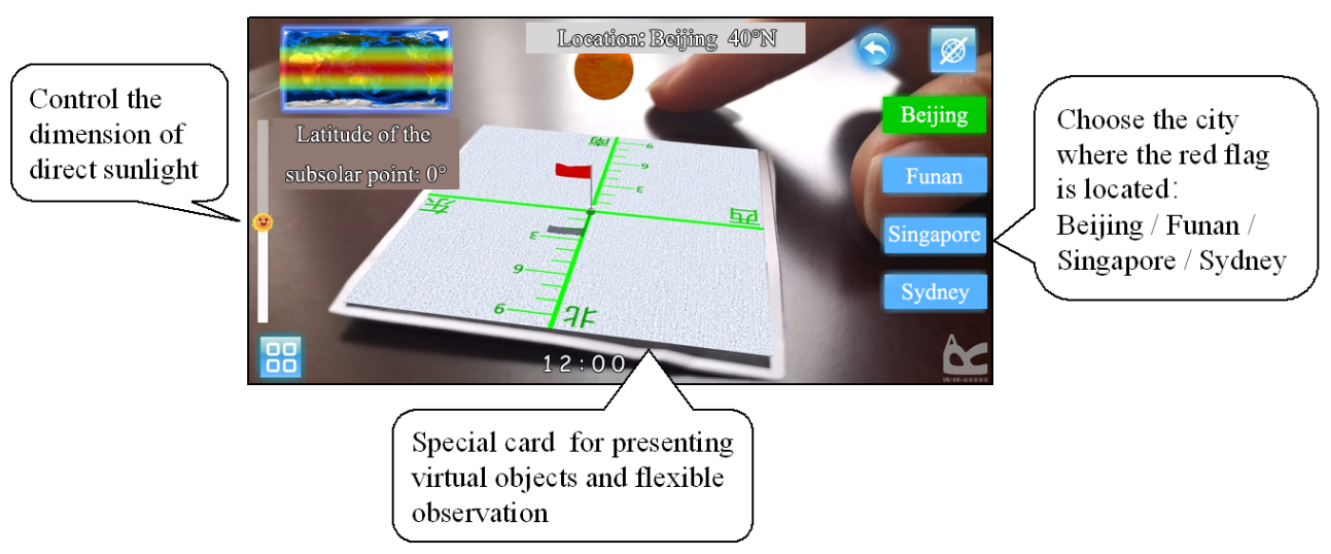

Figure 3. Experiment based on AR image. 


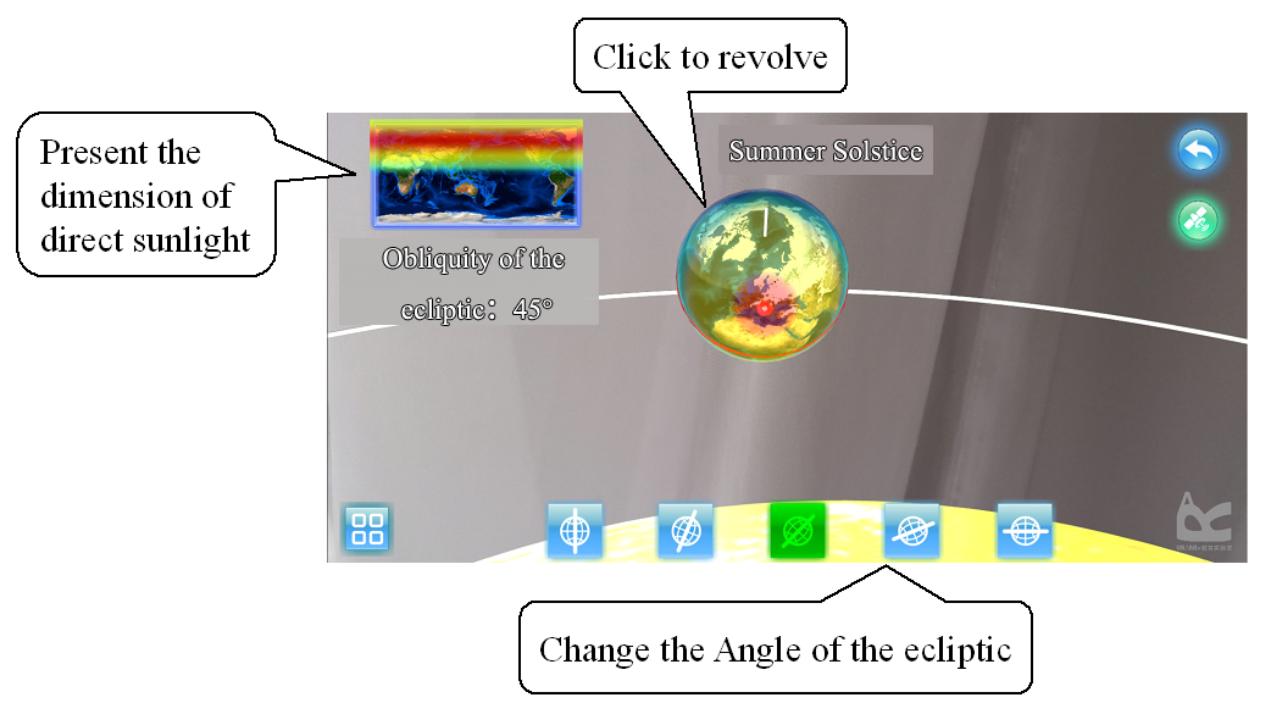

Figure 4. Experiment based on gyroscope.

\subsection{The Education Context}

In order to evaluate the effectiveness of scientific inquiry activities based on the AR environments integrated with the EIA model, a study was conducted for the "Earth's Rotation and Revolution" unit of a primary school science course.

A total of 209 fifth-grade students (10- or 11-year olds) from three parallel classes in a primary school in Anhui, China participated in this study. Each class is a separate study group with about 70 students (70 is a common class size for most public primary schools in that region). The students took science classes for three hours a week and were taught by the same science teacher. They have experienced learning with AR environments several times, so they have no difficulty in using AR in class.

These students complete the learning content of the earth's rotation and revolution in two weeks. Students in the first class learn with AR environments integrated with the EIA model and experience the three phases, Experience-Inquiry-Application, at every lesson, and they use AR in every phase.

Students in the second class learn with AR environments integrated with the inquiry model and take five steps in every lesson: (1) situational contextualization, (2) inspirational thinking, (3) independent investigation, (4) cooperation and communication, and (5) summarization and improvement, using AR in phase 1 and phase 3.

Students in the third class learn with general media environments integrated with the inquiry model and learn with the same sequences as students in the second class with general media, such as pictures and videos.

\section{Methods}

This study uses a mixed research method to investigate the differences in the learning achievement, scientific literacy, and cognitive load of the three groups of students who learned with different activities in different environments, and to explain the experimental results through interviews with students and the local schoolteachers. This study aims to investigate the following research questions:

Q1: Can an AR learning environment integrated with the EIA inquiry model enhance students' scientific learning performance in learning activities?

Q2: Can an AR learning environment integrated with the EIA inquiry model enhance students' scientific literacy in learning activities?

Q3: Will an AR learning environment integrated with the EIA inquiry model increase students' cognitive load in learning activities? 


\subsection{Participants}

In order to clarify the effectiveness of the EIA model, this study controls the variables and the teaching model as shown in Table 1 . The Chinese traditional inquiry model, a nationally accepted model, was used by the Control Group. The students from three classes were divided into three groups by cluster assignments, with their routine homerooms as group assignments. Since some students failed to attend all the lessons, 189 out of 209 data sets were considered valid and complete for future analysis.

Table 1. Study groups.

\begin{tabular}{ccccc}
\hline Group & Class & Conditions & $\begin{array}{c}\text { Class } \\
\text { Size }\end{array}$ & Valid Data \\
\hline Experimental Group 1 & Class 6 & $\begin{array}{c}\text { AR environments integrated } \\
\text { with the EIA model }\end{array}$ & 70 & 62 \\
\hline Experimental Group 2 & Class 5 & $\begin{array}{c}\text { AR environments integrated } \\
\text { with the inquiry model }\end{array}$ & 70 & 66 \\
\hline Control Group & Class 1 & $\begin{array}{c}\text { General media environments } \\
\text { integrated with the } \\
\text { inquiry model }\end{array}$ & 69 & 61 \\
\hline
\end{tabular}

One of the authors carried out the lessons for all the classes to ensure the consistency between the activities and the processes of the models. Five science teachers from the primary school audited all the lessons. They were asked to participate in a group interview after the lessons.

\subsection{Experimental Procedure}

Figure 5 gives an outline of the procedure of the study. Before the first lesson, the three groups of students took a pre-test about scientific knowledge and scientific literacy. At the end of the third lesson, students spent five minutes completing a questionnaire regarding cognitive load. After the third lesson, the students took the post-test for comparing the achievements and improvements in scientific literacy. After the pre-processing of pre- and post-test data, six students with good performance in Experimental Group 1 were selected for a group interview, and the five primary science teachers were interviewed to give their evaluation of the EIA model. Figure 6 shows the teacher and the students are learning by AR on the tablets in the classroom.

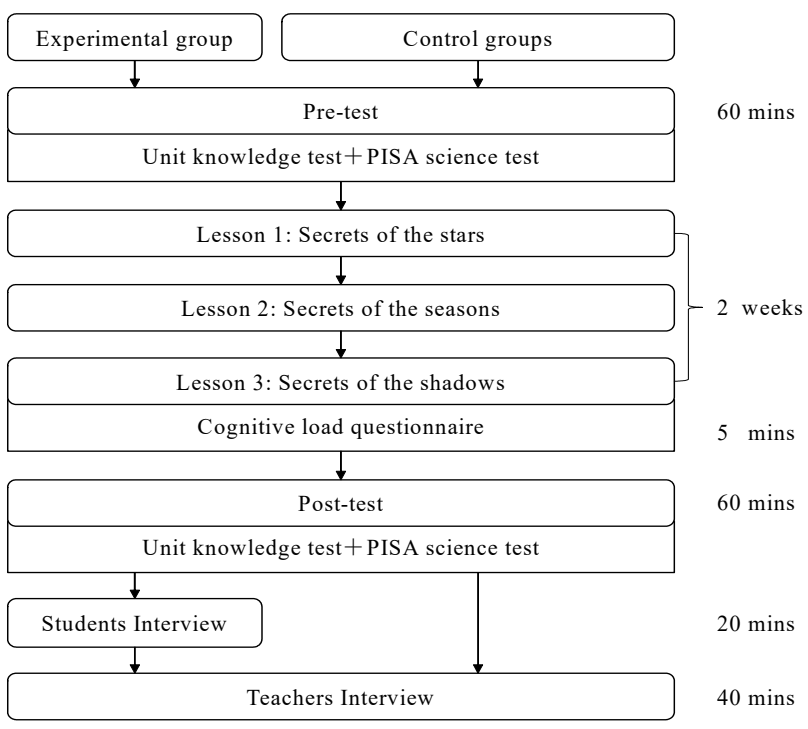

Figure 5. Diagram of the experimental design. 

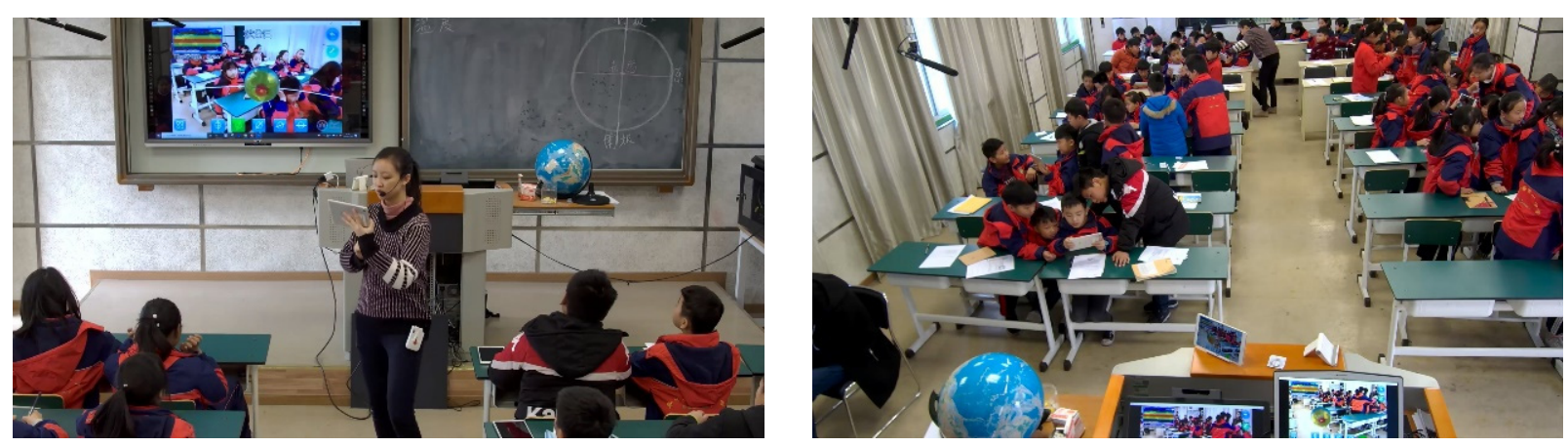

Figure 6. AR teaching and learning in the classroom.

\subsection{Instruments}

The instruments in this study included a pre-test, a post-test, and a cognitive load questionnaire.

The pre-test and post-test both contained a unit knowledge test and a scientific literacy test. The unit test was from a publicly accepted book written by a nationally renowned science teacher [39]. The unit test measured students' learning achievements by investigating their understanding of knowledge. It is divided into three parts with 16 questions. The scientific literacy tests were from two PISA science tests with the same level of difficulty in 2015 [40], including four questions.

This study also used the cognitive load questionnaire developed by Hwang, Yang and Wang [28]. It consists of eight items with a seven-point Likert rating scheme, including five items for "mental load" and three for "mental effort". The Cronbach's $\alpha$ values of the two dimensions provided by the original study were 0.85 and 0.86 , respectively, implying highly acceptable reliability for evaluating students' cognitive load during the learning activity. The Cronbach's alpha values of the questionnaire and the two dimensions in this study are $0.90,0.86$, and 0.77 , respectively.

In addition, semi-structured interview outlines were prepared to in order to conduct group interviews with students and then teachers.

\subsection{Data Analysis}

Tests for homogeneity of variance were conducted for each feature to determine the normality of data distributions. If the $p<0.05$, it means a violation of the assumption and Kruskal-Wallis test for nonparametric comparisons was applied. Otherwise, one-way ANCOVA was used to explore whether there were differences among different groups. Bonferroni multiple comparison corrections were conducted post-hoc.

\section{Results}

In summary, the results of data analysis reveal that both EIA inquiry model and AR learning environments can significantly positively improve students' achievement. Moreover, the EIA model is highly adaptable to the AR environment, and the combination of the two can effectively improve students' scientific literacy and reduce their cognitive load.

\subsection{Analysis of Learning Achievement}

The learning achievement is an essential factor for the purpose of this study. After the study, the analysis of covariance (ANCOVA) was used to test the difference among the three groups by using the pre-test scores as the covariate and the post-test scores as dependent variables, as shown in Table 2. The adjusted mean value of the post-test scores were 48.71, 49.49, and 37.87 for the Experimental Group 1, Experimental Group 2, and Control Group, respectively, while the standard error values were around 1.70. According to the results $(\mathrm{F}=15.33, p<0.001)$, there was a significant difference among the three groups. 
Table 2. Descriptive data and ANCOVA of the post-test results on learning achievement.

\begin{tabular}{lcccccc}
\hline \multirow{2}{*}{ Group } & \multirow{2}{*}{ N } & \multicolumn{2}{c}{ Unadjusted } & \multicolumn{2}{c}{ Adjusted } & \multirow{2}{*}{ Mean } \\
& & SD & Mean & SE & \\
\hline Experimental Group 1 & 62 & 53.85 & 16.19 & 48.71 & 1.80 & \\
Experimental Group 2 & 66 & 44.23 & 14.79 & 49.49 & 1.76 & \multirow{2}{*}{$15.33^{* * *}$} \\
$\quad$ Control Group & 61 & 38.33 & 13.34 & 37.87 & 1.67 & \\
\hline${ }^{* * *} p<0.001$. & & & & &
\end{tabular}

When comparing the learning achievement among groups, pairwise comparison of the marginal mean of each group was carried out based on the results of ANCOVA. The results revealed that the scores of students in Control Group were significantly different from those in the Experimental Group 1 (MD (Mean Difference) $=10.84, p<0.001$ ) and Experimental Group $2(\mathrm{MD}=11.62, p<0.001)$.

In view of the analysis of students' learning achievement above, it can be seen that different media conditions and teaching models have a significant influence on students knowledge construction. As students learning in AR environments got better scores than students learning in general media environments, AR technology is confirmed to be beneficial for the learning activities of the unit "Earth's Rotation and Revolution".

\subsection{Analysis of Scientific Literacies}

This study focused on scientific literacy and evaluated students' scientific literacy by two PISA science tests before and after the study. Similarly, the analysis of covariance (ANCOVA) was used to test the difference among the three groups by using the pretest scores as the covariate and the post-test scores as dependent variables, as shown in Table 3. The adjusted mean value of the post-test scores were 11.20, 10.10, and 9.38 for the Experimental group 1, Experimental group 2, and Control Group, respectively, while the standard error values were around 0.37. According to the results $(F=6.00$, $p<0.05)$, there was a significant difference among the three groups on the improvement of scientific literacy.

Table 3. Descriptive data and ANCOVA of the post-test results on scientific literacy.

\begin{tabular}{|c|c|c|c|c|c|c|}
\hline \multirow{2}{*}{ Group } & \multirow{2}{*}{$\mathbf{N}$} & \multicolumn{2}{|c|}{ Unadjusted } & \multicolumn{2}{|c|}{ Adjusted } & \multirow[b]{2}{*}{$\mathbf{F}$} \\
\hline & & Mean & SD & Mean & SE & \\
\hline Experimental Group 1 & 62 & 11.34 & 3.58 & 11.20 & 0.37 & \\
\hline Experimental Group 2 & 66 & 10.24 & 3.15 & 10.10 & 0.36 & $6.00 * *$ \\
\hline Control Group & 61 & 9.08 & 3.60 & 9.38 & 0.38 & \\
\hline
\end{tabular}

Based on the results of covariance analysis, pairwise comparison of the marginal mean of each group showed that the scores of students in the Experimental Group 1were significantly higher than those in Control Group (MD = 1.82, $p<0.01)$.

On the grounds of the analysis of students' scientific literacy test results, the AR learning environments integrated with the EIA model have a significant positive impact on the improvement of students' scientific literacies. Although students in each group got higher scores on the PISA science test after lessons, students learning under AR environments with the EIA model in Experimental Group 1 made more progress than those learning without AR in Control Group. Furthermore, because of the fact that students in Experimental Group 1 also did better than students in Experimental Group 2, the EIA model can be considered as adapting to learning with AR environments well and contributing to enhancing students' scientific literacy.

\subsection{Analysis of Cognitive Load}

Although cognitive load has been the focus of many researchers interested in AR education systems, the relation between AR and cognitive load is still unclear [4,5]. Students 
were required to evaluate their cognitive load during the lessons after the experiment. The results of analysis of variance $(\mathrm{F}=12.40, p<0.001)$ in Table 4 . illustrated that students in different groups were in different levels of cognitive load.

Table 4. Descriptive data and ANOVA of the post-questionnaire results on cognitive load.

\begin{tabular}{|c|c|c|c|c|c|c|c|}
\hline \multirow{2}{*}{$\begin{array}{c}\text { Variable and } \\
\text { Source }\end{array}$} & \multirow{2}{*}{ Group } & \multirow{2}{*}{$\mathbf{N}$} & \multicolumn{2}{|c|}{ Unadjusted } & \multicolumn{2}{|c|}{ Adjusted } & \multirow{2}{*}{$\mathbf{F}$} \\
\hline & & & Mean & SD & Mean & SE & \\
\hline \multirow{3}{*}{ Cognitive load } & Experimental Group 1 & 62 & 2.06 & 0.77 & 2.06 & 0.11 & \multirow{3}{*}{$12.40^{* * *}$} \\
\hline & Experimental Group 2 & 66 & 2.83 & 1.07 & 2.83 & 0.11 & \\
\hline & Control Group & 61 & 2.31 & 0.78 & 2.31 & 0.11 & \\
\hline \multirow{3}{*}{ Mental load } & Experimental Group 1 & 62 & 2.00 & 0.78 & 2.00 & 0.12 & \multirow{3}{*}{$11.01^{* * *}$} \\
\hline & Experimental Group 2 & 66 & 2.75 & 1.09 & 2.75 & 0.11 & \\
\hline & Control Group & 61 & 2.26 & 0.82 & 2.26 & 0.12 & \\
\hline \multirow{3}{*}{ Mental effort } & Experimental Group 1 & 62 & 2.15 & 1.02 & 2.15 & 0.14 & \multirow{3}{*}{$9.70^{* * *}$} \\
\hline & Experimental Group 2 & 66 & 2.95 & 1.19 & 2.96 & 0.13 & \\
\hline & Control Group & 61 & 2.40 & 0.98 & 2.40 & 0.14 & \\
\hline
\end{tabular}

Furthermore, pairwise comparison of the marginal mean of each group showed that the cognitive load level of students in Experimental Group 2 was significantly higher than that of students in Experimental Group $1(\mathrm{MD}=0.77, p<0.001)$ and Control Group $(\mathrm{MD}=0.51, p<0.01)$. Considering the instructional model and media environments of each group, the results stated that the AR environments combined with the traditional inquiry model had a negative influence on students' cognitive load, which meant that the instructional model affected on students' cognitive load when they learned with AR environments, and the EIA model is conducive to reducing students' cognitive load in AR learning environments.

Further analysis from the aspects of mental load and mental effort were done to reveal how AR environments and models impact students' cognitive load.

\subsubsection{Mental Load}

Table 4 also demonstrated the results of analysis of variance on mental load of students in each group $(\mathrm{F}=11.01, p<0.001)$, and statistical evidence concluded that there is a significant difference among the level of mental load of groups.

In terms of pairwise comparison of the marginal mean of Experimental Group 2 and other groups, the results exposed that students in Experimental Group 2 had a significant higher mental load level than students in Experimental Group 1 (MD $=0.74, p<0.001$ ) and Control Group (MD $=0.49, p<0.01$ ). Students learning with AR environments and traditional inquiry model may have difficulties in understanding content and answering questions in learning activities.

Taking the pairwise comparison results (MD $=-0.26, p>0.05)$ for Experimental Group 1and Control Group into account, the mental load of students in the Experimental Group was even lower than that of students in Control Group, which indicated that AR environments with the EIA model were powerful and peculiar for reducing cognitive load.

The analysis results of students' mental load above reveal the interaction effect of the media and instructional model. This conclusion may explain the uncertainty of AR's influence on cognitive load. Media with an inappropriate instructional model may increase students' mental load, while media with matched model will reduce the learning difficulties.

\subsubsection{Mental Effort}

The results of analysis of variance on mental effort of students in each group $(\mathrm{F}=9.70$, $p<0.001$ ) is also shown in Table 4. There was also a significant difference among the level of mental effort of students in each group. 
As for pairwise comparison of the marginal means of each group on mental effort, students from Experimental Group 2 put in significantly more effort than students from Experimental Group $1(\mathrm{MD}=0.81, p<0.001$ ) and Control Group (MD $=0.56, p<0.05)$. The reason for this phenomenon may be related to the mental effort caused by learning with media and the model which do not fit very well with each other.

Although students in Experimental Group 2 had higher levels of cognitive load, they got better learning achievement than students in Control Group. This may be because students in Experimental Group 2 put in more mental effort, so they engaged in the activities more. Therefore, AR environments truly have positive effects on increasing students' involvement. Consulting the analysis of scientific literacy and cognitive load, students learning with AR environments and the EIA model in general had significant progress in scientific literacy with low cognitive load.

\subsection{Results of Student Interviews}

Six students in the Experimental Group 1, selected as described in Section 4.2, were interviewed on AR environments with the EIA model's contribution to students' scientific literacy.

In the interview, students were able to talk about the phenomenon observed and the knowledge learned in the class, which indicated that the students had a deep understanding on the learning activities and content. Thanks to the AR environment, students stated that they had more opportunities to operate by themselves and make personalized observations. Under the activities guided by the EIA model, students argued that they had more time for group cooperation and communication in class, and they made more connections from the scientific explorations in class to daily life. In their opinion, their skills related to inquiry ability were improved and they could imagine continuous animations about scientific phenomena. In addition, they said they could discover more ties between knowledge and life.

To evaluate the EIA model, the researcher designed questions to evaluate their perception of outcomes of each phase and guided them to compare the activities they had in the AR lessons with their usual learning experience. In the experience stage, students believed that the situation introduced by EIA model was able to not only stimulate their interest but also make them focus more on what they will learn. When they communicated with their colleagues and teacher, the AR learning environments supported their consideration and expression with dynamic features of visualizations. In the inquiry stage, students claimed that the mechanism of AR environments supported them to change their perspectives of observation flexibly, so that they got a stronger sense of presence and immersion. At the same time, they learned how to explore a science question step by step with AR, so they knew the inquiry process better after the activities. In the application stage, the new problems introduced by the teacher enabled them to connect learning content with situations in daily life, which surprised them and let them discover the connections between different phenomena. In general, they had more interest in further exploration in life after the lessons.

\subsection{Results of Teacher Interviews}

The five teachers, as described in Section 4.1, were invited for an interview themed on the advantages and disadvantages of the EIA model.

When asked about the AR environments, the teachers regarded AR as a breakthrough technology in teaching Earth's rotation and revolution. The AR learning environments allowed teachers and students to observe the earth from the perspective of real space and set up a special experimental platform for them to carry out experiments that could only be understood by students through videos, such as the Foucault pendulum.

As for the instructional model, the teachers stated that the EIA model greatly improved the efficiency of teaching and learning activities. In this study, the researchers used three lessons to finish the unit, while they usually spent seven lessons covering equal content. 
Thus, the teachers proposed that the EIA model could be used for integrated modular teaching. Each phase of the model could be practiced in a lesson to extend the content and keep usual class hours.

Generally speaking, the EIA model was accepted by teachers. The teachers admitted that students learnt to rely on themselves under the model, and this transformation of learning style can improve the adaptability and flexibly of learning activities. They believed students with different cognition styles could learn knowledge they favor under the EIA model.

\section{Discussion and Conclusions}

This study found that AR environments can significantly improve students' learning achievement and cognitive load. Since the EIA model is highly adaptable to the AR learning environments, the combination of the two can effectively enhance students' scientific literacy and reduce their cognitive load.

In this study, students obtained better learning achievement and higher cognitive load when they learned based on AR environments and traditional instructional model. Wang, et al. [41] stated that the higher the interaction complexity is, the higher the mental effort and the better the learning performance in mobile learning will be. Since AR environments combine objects in real world and virtual world, students have more opportunities to interact with more factors during learning activity. This, to some extent, constitutes a partial reason that students in Experiment Group 2 achieved higher performance scores compared to the Control Group, but also had a higher cognitive load. According to Sweller (2011), the extent to which cognitive load operates is inherently complicated, and high cognitive load can potentially dampen students' motivation. In this study, since students in Experiment Group 2 did not obtain a head-start advantage in terms of scientific literacy, the use of AR under such context may cause spikes in cognitive load, thus underperforming in learning activities and scientific literacies. Such findings are supported by the research results from Hui-Chun [42], that without proper treatment, the performance of students using those existing online learning strategies, known to be "effective", might be disappointing or may even negatively affect the students' learning achievements.

According to this study, students learning based on AR environments with the EIA instructional model had significantly lower levels of cognitive load compared with students learning in other conditions, which suggests the instructional model could be a crucial factor that influences students' cognitive load. This result shows that a high reality-related situation in AR tools would reduce the distraction caused by AR technology, which leads to a proper cognitive load level. When AR technology was used in learning activities, students needed more mental effort to complete their tasks; however, the EIA model may reduce their mental load by inspiring the association with learning content and situations in daily life. So, students learning based on AR environments with the EIA model spend as much mental effort as they used in general classes.

In this study, the EIA model demonstrated its ability in enhancing students' scientific literacy, especially under AR learning activities. Some reasons might be that the highlights of the model align well with the three aspects of scientific literacy that the PISA tests assess: collecting evidence, processing information, and communication and presentation are emphasized in each phase to ensure the goal of inquiry. These activities are beneficial for students to improve their scientific literacies according to PISA, including explaining phenomena scientifically, evaluating and designing scientific enquiry, and interpreting data and evidence scientifically [24].

AR learning environments, when integrated with the EIA model, not only offer students platforms to operate and control objects, but also inspire more communication and expression. By exploring in interactively related worlds of virtuality and reality, students will get more profound learning experiences; moreover, dynamic visualization features in AR learning environments also work as scaffolds to support students' expression. Under the EIA model, students learning with AR environments showed more interest, concen- 
trated better, and possessed a deeper sense of presence. They had stronger willingness to work with others and tended to explore new situations. Although students who learned under the AR and EIA models did not significantly outperform students who learned under AR-only, they still outperformed students who had EIA-only environments or neither environment in terms of scientific literacy.

To promote the implementation of virtual experiments for scientific inquiry activities and make use of AR learning environments in primary school for future studies, additional measures and cautions below should be considered. First, one can consider evaluating the EIA model by means of a concept map or other metrics. By asking the students to draw a concept map whenever they learn with AR conditions and the EIA model, this serves as good artifacts to support their learning. Thus, the EIA model could be tested in each phase for further adjustment. Moreover, one can extend the EIA model into the design of AR learning environments and inspire the designers and developers to meet teachers' needs, and help to solve the supply difficulties in virtual environments for scientific inquiry activities.

It is worth noting that we have only tested the role of the EIA model in science lessons, and the role of this model still needs more research. In addition, the students participating in the study have experience in learning using AR technology, so they may be more adaptable to AR tools than other students.

Author Contributions: Conceptualization, Y.Y. and S.C.; methodology, Y.Y.; software, Y.Y.; validation, Y.Y., J.L. and X.J.; formal analysis, Y.Y.; investigation, Y.Y., J.L. and X.J.; resources, S.C.; data curation, Y.Y., J.L. and X.J.; writing—original draft preparation, Y.Y. and Y.W.; writing-review and editing, Y.W.; visualization, Y.Y. and Y.W.; supervision, S.C.; project administration, S.C.; funding acquisition, S.C. All authors have read and agreed to the published version of the manuscript.

Funding: This work was supported by the National Natural Science Foundation of China: 61977007.

Conflicts of Interest: The authors declare no conflict of interest.

\section{References}

1. Azuma, R.T. A Survey of Augmented Reality. Presence Teleoperators Virtual Environ. 1997, 6, 355-385. [CrossRef]

2. Azuma, R.; Baillot, Y.; Behringer, R.; Feiner, S.; Julier, S.; MacIntyre, B. Recent advances in augmented reality. IEEE Eng. Med. Boil. Mag. 2001, 21, 34-47. [CrossRef]

3. Ibáñez, M.-B.; Delgado-Kloos, C. Augmented reality for STEM learning: A systematic review. Comput. Educ. 2018, 123, 109-123. [CrossRef]

4. Wu, H.-K.; Lee, S.W.-Y.; Chang, H.-Y.; Liang, J.-C. Current status, opportunities and challenges of augmented reality in education. Comput. Educ. 2013, 62, 41-49. [CrossRef]

5. Akçayır, M.; Akçayır, G. Advantages and challenges associated with augmented reality for education: A systematic review of the literature. Educ. Res. Rev. 2017, 20,1-11. [CrossRef]

6. Ministry of Education of the People's Republic of China. A Report from the Ministry of Education about Strengthening the Construction of Experiment Teaching in Primary and Secondary Schools. Available online: http://www.moe.gov.cn/srcsite/A0 6/s3321/201911/t20191128_409958.html (accessed on 12 November 2019).

7. Yang, Y.; Ning, F.; Zhu, T.; Bayarmaa, T.-I.; Ma, N. The behavioral intentions of K-12 teachers in adopting augmented reality applications. In Proceedings of the International Conference on Education and E-Learning, Singapore, 24-25 September 2018. Available online: https:/ / www.aztechcouncil.org/event/8th-annual-international-conference-on-education-e-learning-eel-20 18/ (accessed on 24 September 2018).

8. Enyedy, N.; Danish, J.A.; DeLiema, D. Constructing liminal blends in a collaborative augmented-reality learning environment. Int. J. Comput. Collab. Learn. 2015, 10, 7-34. [CrossRef]

9. Yoon, S.A.; Wang, J. Making the Invisible Visible in Science Museums Through Augmented Reality Devices. TechTrends 2013, 58, 49-55. [CrossRef]

10. Chien, Y.-C.; Su, Y.-N.; Wu, T.-T.; Huang, Y.-M. Enhancing students' botanical learning by using augmented reality. Univers. Access Inf. Soc. 2017, 18, 231-241. [CrossRef]

11. Chen, C.-H.; Chou, Y.-Y.; Huang, C.-Y. An Augmented-Reality-Based Concept Map to Support Mobile Learning for Science. Asia-Pac. Educ. Res. 2016, 25, 567-578. [CrossRef]

12. Zimmerman, H.T.; Land, S.M.; Jung, Y.J. Using augmented reality to support children's situational interest and science learning during context-sensitive informal mobile learning. In Mobile, Ubiquitous, and Pervasive Learning; Springer: Cham, Switzerland, 2015; pp. 101-119. [CrossRef] 
13. Tarng, W.; Ou, K.-L.; Lu, Y.-C.; Shih, Y.-S.; Liou, H.-H. A Sun Path Observation System Based on Augment Reality and Mobile Learning. Mob. Inf. Syst. 2018, 2018, 1-10. [CrossRef]

14. Tarng, W.; Lin, Y.-S.; Lin, C.-P.; Ou, K.-L. Development of a Lunar-Phase Observation System Based on Augmented Reality and Mobile Learning Technologies. Mob. Inf. Syst. 2016, 2016, 1-12. [CrossRef]

15. Yoon, S.A.; Anderson, E.; Park, M.; Elinich, K.; Lin, J. How augmented reality, textual, and collaborative scaffolds work synergistically to improve learning in a science museum. Res. Sci. Technol. Educ. 2018, 36, 261-281. [CrossRef]

16. Hendajani, F.; Hakim, A.; Lusita, M.D.; Saputra, G.E.; Ramadhana, A.P. 3D animation model with augmented reality for natural science learning in elementary school. In 4th International Seminar of Mathematics, Science and Computer Science Education; Aisyah, S., Samsudin, A., Al Jupri, Kusumawaty, D., Nuraeni, E., Yulianti, K., Hasanah, L., Rusyati, L., Megasari, R., Rosjanuardi, R., et al., Eds.; Journal of Physics Conference Series; IOP Publishing Ltd.: Bristol, UK, 2018; Volume 1013, pp. 1-7. Available online: https:/ /iopscience.iop.org/article/10.1088/1742-6596/1013/1/012154/meta (accessed on 14 October 2017).

17. Cai, S.; Chiang, F.-K.; Sun, Y.; Lin, C.; Lee, J.J. Applications of augmented reality-based natural interactive learning in magnetic field instruction. Interact. Learn. Environ. 2016, 25, 778-791. [CrossRef]

18. Cai, S.; Wang, X.; Chiang, F.-K. A case study of Augmented Reality simulation system application in a chemistry course. Comput. Hum. Behav. 2014, 37, 31-40. [CrossRef]

19. Zimmerman, H.T.; Land, S.M.; McClain, L.R.; Mohney, M.R.; Choi, G.W.; Salman, F.H. Tree Investigators: Supporting families' scientific talk in an arboretum with mobile computers. Int. J. Sci. Educ. Part B 2013, 5, 44-67. [CrossRef]

20. Chang, S.-C.; Hwang, G.-J. Impacts of an augmented reality-based flipped learning guiding approach on students' scientific project performance and perceptions. Comput. Educ. 2018, 125, 226-239. [CrossRef]

21. Wu, P.-H.; Hwang, G.-J.; Yang, M.-L.; Chen, C.-H. Impacts of integrating the repertory grid into an augmented reality-based learning design on students' learning achievements, cognitive load and degree of satisfaction. Interact. Learn. Environ. 2017, 26, 221-234. [CrossRef]

22. Turiman, P.; Omar, J.; Daud, A.M.; Osman, K. Fostering the 21st Century Skills through Scientific Literacy and Science Process Skills. Procedia-Soc. Behav. Sci. 2012, 59, 110-116. [CrossRef]

23. National Research Council. Next Generation Science Standards: For States, By States; The National Academies: Washington, DC, USA, 2013. [CrossRef]

24. OECD. PISA 2018 Assessment and Analytical Framework. 2019. Available online: https://www.oecd-ilibrary.org/education/ pisa-2018-assessment-and-analytical-framework_b25efab8-en (accessed on 14 November 2021).

25. Ministry of Education of the People's Republic of China. Curriculum Standards of Primary School Science Course; Beijing Normal University Publishing Group: Beijing, China, 2017. Available online: http:/ /www.moe.gov.cn/srcsite/A26/s8001/201702/t201 70215_296305.html (accessed on 14 November 2021).

26. Thees, M.; Kapp, S.; Strzys, M.P.; Beil, F.; Lukowicz, P.; Kuhn, J. Effects of augmented reality on learning and cognitive load in university physics laboratory courses. Comput. Hum. Behav. 2020, 108, 106316. [CrossRef]

27. Kalyuga, S.; Sweller, J. Rapid dynamic assessment of expertise to improve the efficiency of adaptive e-learning. Educ. Technol. Res. Dev. 2005, 53, 83-93. [CrossRef]

28. Hwang, G.-J.; Yang, L.-H.; Wang, S.-Y. A concept map-embedded educational computer game for improving students' learning performance in natural science courses. Comput. Educ. 2013, 69, 121-130. [CrossRef]

29. Bybee, R. Guest Editorial: The BSCS 5E Instructional Model: Personal Reflections and Contemporary Implications. Sci. Child. 2014, 51, 10-13. [CrossRef]

30. NASA. 5Es Overview: "The 5E Instructional Model". Available online: http://www.nasa.gov/audience/foreducators/ nasaeclips/5eteachingmodels/index.html (accessed on 29 December 2008).

31. Eisenkraft, A. Expanding the 5E Model: A proposed 7E model emphasizes "transfer of learning" and the importance of eliciting prior understanding. J. Sci. Teach. 2003, 70, 58-59.

32. Schwarz, C.V.; Gwekwerere, Y.N. Using a guided inquiry and modeling instructional framework (EIMA) to support preservice K-8 science teaching. Sci. Educ. 2006, 91, 158-186. [CrossRef]

33. Marshall, J.C.; Horton, B.; Smart, J. $4 \mathrm{E} \times 2$ Instructional Model: Uniting Three Learning Constructs to Improve Praxis in Science and Mathematics Classrooms. J. Sci. Teach. Educ. 2009, 20, 501-516. [CrossRef]

34. Gunckel, K.L. Mediators of a Preservice Teacher's Use of the Inquiry-Application Instructional Model. J. Sci. Teach. Educ. 2011, 22, 79-100. [CrossRef]

35. He, K.; Wu, J. The Third Academic Paper of Teaching Models Research Series about Integrating Information Technology into Curriculum-Inquiry Teaching Model. Mod. Educ. Technol. 2008.

36. Ruiz-Ariza, A.; Casuso, R.A.; Suarez-Manzano, S.; Martínez-López, E.J. Effect of augmented reality game Pokémon GO on cognitive performance and emotional intelligence in adolescent young. Comput. Educ. 2018, 116, 49-63. [CrossRef]

37. Efstathiou, I.; Kyza, E.A.; Georgiou, Y. An inquiry-based augmented reality mobile learning approach to fostering primary school students' historical reasoning in non-formal settings. Interact. Learn. Environ. 2017, 26, 22-41. [CrossRef]

38. Hsiao, H.-S.; Chang, C.-S.; Lin, C.-Y.; Wang, Y.-Z. Weather observers: A manipulative augmented reality system for weather simulations at home, in the classroom, and at museum. Interact. Learn. Environ. 2013, 24, 205-223. [CrossRef] 
39. Ding, Y. The Teaching and Learning of "Earth and Space" in Primary Science: Let the Children Like Astronomy and Geography More; Ningbo Publishing House: Ningbo, China, 2013. Available online: http:/ / e.dangdang.com/products/1900362455.html (accessed on 29 October 2021).

40. OECD. PISA2015-Released-FT-Cognitive-Items.pdf. Available online: http://www.oecd.org/pisa/test/PISA2015-Released-FTCognitive-Items.pdf (accessed on 20 February 2015).

41. Wang, C.; Fang, T.; Miao, R. Learning performance and cognitive load in mobile learning: Impact of interaction complexity. J. Comput. Assist. Learn. 2018, 34, 917-927. [CrossRef]

42. Hui-Chun, C. Potential Negative Effects of Mobile Learning on Students' Learning Achievement and Cognitive Load-A Format Assessment Perspective. J. Educ. Technol. Soc. 2014, 17, 332-344. 